\title{
Association of seasonality and serum albumin concentration with vitamin $D$ deficiency in subjects with chronic hepatitis $C$ infection living in a sunny country
}

\author{
Henrique Pott-Junior ${ }^{1,2, *}$ (1), Camila Luzeiro², Jorge Figueiredo Senise ${ }^{2}$ and Adauto Castelo 2 \\ 'Department of Medicine, Universidade Federal de São Carlos (UFSCar), $13565-905$ São Carlos, Brazil: ${ }^{2}$ Division of \\ Infectious Diseases, Universidade Federal de São Paulo (UNIFESP), 04023-062 São Paulo, Brazil
}

Submitted 28 February 2019: Final revision received 5 September 2019: Accepted 24 September 2019: First published online 9 March 2020

\begin{abstract}
Objective: This study aimed to analyse the relationship between vitamin D deficiency and the season when the blood sample was obtained from subjects with chronic hepatitis C (CHC) infection.

Design: A cross-sectional study was conducted on a representative sample. Vitamin D deficiency was defined as a serum 25-hydroxyvitamin D [25(OH)D] concentration $<50 \mathrm{nmol} / \mathrm{l}$, based on the values set forth by the Endocrine Society guideline for higher-risk populations. Seasonality was defined according to solstices and equinoxes. The association of seasonality and clinical/laboratory characteristics with vitamin D deficiency was assessed using a multivariate logistic regression analysis.

Setting: NUPAIG Viral Hepatitis Outpatient Clinic of the Universidade Federal de São Paulo - Brazil.

Participants: Adult subjects with CHC infection ( $n$ 306).

Results: The prevalence of vitamin D deficiency was $16 \%$, whereas the median serum $25(\mathrm{OH}) \mathrm{D}$ concentration was 87 (interquartile range, 59 ; third quartile $=118$ ) $\mathrm{nmol} / \mathrm{l}$. Serum concentration was consistently lower in samples collected in spring and winter than in other seasons. In multivariate analysis, vitamin D deficiency was found to be independently associated with male gender, serum albumin concentration and with samples drawn in winter and spring.

Conclusions: The findings show not only the relevance to consider season as a factor influencing $25(\mathrm{OH}) \mathrm{D}$ concentration but also the need to actively screen for hypovitaminosis D in all patients with $\mathrm{CHC}$ infection, especially in females and those with low albumin concentration.
\end{abstract}

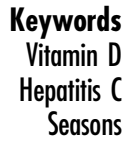

Keywords Hepatitis C Seasons
Vitamin D deficiency is a major public health problem worldwide and is often reported in people with liver diseases. According to literature, the prevalence of vitamin D deficiency among patients with chronic hepatitis $\mathrm{C}$ (CHC) infection is $>60 \%$ and can further vary based upon the geographical region $^{(1-3)}$.

Nonetheless, despite its continuous improvements, routine assessment of vitamin D status still faces several challenges that are often neglected in clinical practice. One of these challenges deals with the lack of optimal and clinically relevant 25-hydroxyvitamin D [25(OH)D] concentration cut-off value to define the fall in serum $25(\mathrm{OH}) \mathrm{D}$ concentration in patients with $\mathrm{CHC}^{(1)}$. Regarding this, except for the Endocrine Society guideline, most recent consensus statements about hypovitaminosis D do not specifically consider diseased populations. Therefore, different cut-off values used in different studies might affect the true prevalence of hypovitaminosis $\mathrm{D}$ in patients with $\mathrm{CHC}$.

Another challenge is the influence of various factors on the serum concentration of $25(\mathrm{OH}) \mathrm{D}$, such as age, skin pigmentation, clothing style, sunscreen use and seasonality ${ }^{(4,5)}$. Regarding this last aspect, others have already discussed the seasonal variation of serum 25(OH)D concentration during the months with the shortest daylight period. And, as pointed out previously, to achieve a correct diagnosis of vitamin D deficiency, blood sampling seasonality should be regarded as an important preanalytical factor ${ }^{(4)}$.

However, despite having consistent evidence about the influence of these factors on serum $25(\mathrm{OH}) \mathrm{D}$ concentration, 
to our knowledge, there is a lack of studies on the relevance of these factors on serum 25(OH)D concentration among patients with $\mathrm{CHC}$.

Therefore, the aim of this cross-sectional study was to evaluate the prevalence of vitamin D deficiency in subjects with $\mathrm{CHC}$ infection. The secondary aim was to assess whether the season when the blood sample was drawn is associated with the presence of vitamin D deficiency.

\section{Methods}

\section{Study population}

Medical records of patients attending the - blinded for peer review - were retrospectively reviewed.

Patients were retrospectively enrolled if they met the following criteria: $\geq 18$ years of age with $\mathrm{CHC}$ infection and having a $25(\mathrm{OH}) \mathrm{D}$ blood test collected at first consultation. Key exclusion criteria included chronic liver disease unrelated to hepatitis $\mathrm{C}$ vírus (HCV) infection, co-infection with HIV or hepatitis B virus and history of past and/or current use of vitamin D supplementation.

\section{Study design}

A cross-sectional study was conducted on 306 subjects with $\mathrm{CHC}$ infection. The following data were gathered from those meeting the inclusion criteria: age, gender, skin colour, presence of any comorbidities, previous treatment experience, severity of liver fibrosis and seasonality of blood sampling. Seasonality was defined according to solstices and equinoxes, that is, winter: June-September; spring: September-December; summer: December-March; and autumn: March-June. Biochemical parameters, including plasma glucose, $25(\mathrm{OH}) \mathrm{D}$, urea, creatinine, aspartate aminotransferase (AST), alanine aminotransferase (ALT), HCV genotype and HCV RNA viral load, were also assessed by commercial laboratory methods. Cases with missing values were deleted listwise, that is, observations with missing values on any of the variables were omitted from the analysis.

Glomerular filtration rate was estimated (eGFR) for each patient using the four-variable Modifications of Diet in Renal Disease (MDRD) study equation ${ }^{(6)}$. The presence of cirrhosis was defined as a Metavir score of $\mathrm{F} 4$ on liver biopsy up to 12 months after first consultation and/or a liver stiffness value $>12.5 \mathrm{kPa}$ and/or an AST-to-platelet ratio index (APRI) value $>2^{(7,8)}$. In case of conflicting fibrosis results according to these methods, biopsy data took precedence. If biopsy data were not available, the FibroScan result was considered. Otherwise, the APRI result was considered.

\section{Biochemical determinations}

In the morning after an overnight fast, venous blood was sampled for measurements of plasma glucose, $25(\mathrm{OH}) \mathrm{D}$, urea, creatinine, AST and ALT following routine biochemical laboratory protocols. Liver transaminases were described as healthy considering 19 and $30 \mathrm{U} / 1$ as its upper limit of normality for women and men, respectively ${ }^{(9)}$.

HCV genotype or subtype was determined using a Real-Time HCV Genotype II assay (Abbott Molecular). Plasma HCV RNA levels were assessed using the HCV COBAS TaqMan Test (version 2.0; Roche Molecular Systems) with a lower limit of quantitation of $12 \mathrm{IU} / \mathrm{ml}$.

All serum 25(OH)D analyses were performed at the same laboratory using Elecsys Vitamin D Total assay (Roche Diagnostics), which is a fully automated electrochemiluminescence protein-binding assay for the quantitation of $25(\mathrm{OH}) \mathrm{D} 3$ and $25(\mathrm{OH}) \mathrm{D} 2$, allowing quantitative determination of total $25(\mathrm{OH}) \mathrm{D}$. It is standardised against liquid chromatography coupled with tandem MS (LC-MS/MS) calibrated using the National Institute of Standards and Technology reference material SRM $2972^{(10,11)}$. The assay has a detection limit of $7.50 \mathrm{nmol} / 1$ and a within-run imprecision (CV) of $18.5 \%$. Notably, a recent study showed a higher performance for the assay in routine laboratory testing: within-run $\mathrm{CV} \leq 7 \%$, within-laboratory $\mathrm{CV}<9.5 \%$, between-laboratory precision $\mathrm{CV} \leq 10 \cdot 1 \%$, and functional sensitivity $<9.8 \mathrm{nmol} / 1$ (at CV $12.9 \%)^{(12)} .25(\mathrm{OH}) \mathrm{D}$ concentrations $<50 \mathrm{nmol} / 1$ were classified as deficiency; those ranging from 250 to $74.9 \mathrm{nmol} / 1$ as insufficiency, and between 75 and $250 \mathrm{nmol} / \mathrm{l}$ as sufficiency ${ }^{(13)}$. As vitamin $\mathrm{D}$ inadequacy is particularly important among patients with a chronic illness, the Endocrine Society have recommended attaining a $25(\mathrm{OH}) \mathrm{D}$ concentration $>75 \mathrm{nmol} / \mathrm{l}$ for higher-risk populations, such as CHC-infected patients. ${ }^{(13)}$ Therefore, we also categorised $25(\mathrm{OH}) \mathrm{D}$ concentration based on this threshold and defined vitamin D adequacy as a $25(\mathrm{OH}) \mathrm{D}$ concentration of $\geq 75 \mathrm{nmol} / \mathrm{l}$.

\section{Statistical methods}

Based on previous findings on the overall prevalence of vitamin D sufficiency in the Brazilian population, we assumed that the prevalence of vitamin D inadequacy for a high-risk population would be around $65 \%(60-70 \%)^{(14-16)}$. Therefore, we calculated a required sample size of 243 patients with an allowable error margin of $6 \%$ and a $95 \%$ CI.

Continuous data are presented as mean (SD) or median (interquartile range, IQR) according to the Shapiro-Wilk test of normality. Categorical variables are presented as counts and percentages. Comparisons between groups were performed using Wilcoxon-Mann-Whitney test for continuous variables, and Pearson's Chi-squared test with Yates' continuity correction for categorical variables. Comparison of differences in the distribution of values among seasons was conducted using Kruskal-Wallis test, followed by a post hoc Dunn test for multiple comparisons. Univariate logistic regression analysis was performed to explore the unadjusted association between variables and vitamin D deficiency. The variables whose univariate 
analysis obtained a $P$-value $<0.25$ and other variables of known clinical relevance were selected for the multivariate analysis. Statistical significance was assessed at a two-sided $P<0.05$. All analyses were conducted using R 3.5.2 (The R Project for Statistical Computing, 2018) in R-studio 1.1.463 (RStudio Inc.).

\section{Results}

The general characteristics of studied population are depicted in Table 1. A total of 306 subjects with $\mathrm{CHC}$ were included in the study. The majority of subjects were males $(162 / 306 ; 53 \%)$ with a mean age of $50 \pm 11$ years. The prevalence of comorbidities was $56 \%$ (169/306); most of the subjects had their first consultation during winter (126/306; $41 \%)$ and had no previous HCV treatment experience $(272 / 306 ; 89 \%)$. HCV genotype 1 was the most frequent $(246 / 306 ; 80 \%)$, and mean baseline HCV RNA viral load was $5.9 \pm 0.7 \log _{10} \mathrm{UI} / \mathrm{ml}$. The prevalence of vitamin D deficiency and insufficiency was $16 \%$ (50/306) and $23 \%$ (71/306), respectively. The median serum concentration of
25(OH)D was 39 (IQR 17), 62 (IQR 11) and 112 (IQR, 47) $\mathrm{nmol} / \mathrm{l}$ in patients with vitamin D deficiency, insufficiency and sufficiency, respectively. Subjects with vitamin D deficiency presented a higher prevalence of unhealthy ALT values, despite having no statistically significant difference in the mean $\operatorname{ALT}$ value $(P=0.5)$. A trend was observed towards having a lower HCV RNA viral load for vitamin D-deficient subjects $\left(6 \pm 0.7 \quad v .5 .8 \pm 0.7 \log _{10} \quad \mathrm{UI} / \mathrm{ml}\right.$, $P=0.06)$.

\section{Seasonality of blood sampling and serum 25(OH) D concentration}

Overall, subjects who have had their blood drawn during summer and autumn showed higher serum 25(OH)D concentrations ( $P=0.01$, with Kruskal-Wallis test). Post hoc multiple comparisons found a statistically significant difference between spring-summer $(P=0.04)$, autumnwinter $(P=0.01)$ and summer-winter $(P=0.009)$ (Fig. 1$)$. The prevalence of vitamin D deficiency was also shown to be statistically higher in spring and winter $(P=0.007)$, without statistically significant differences between them.

Table 1 Characteristics of the study population

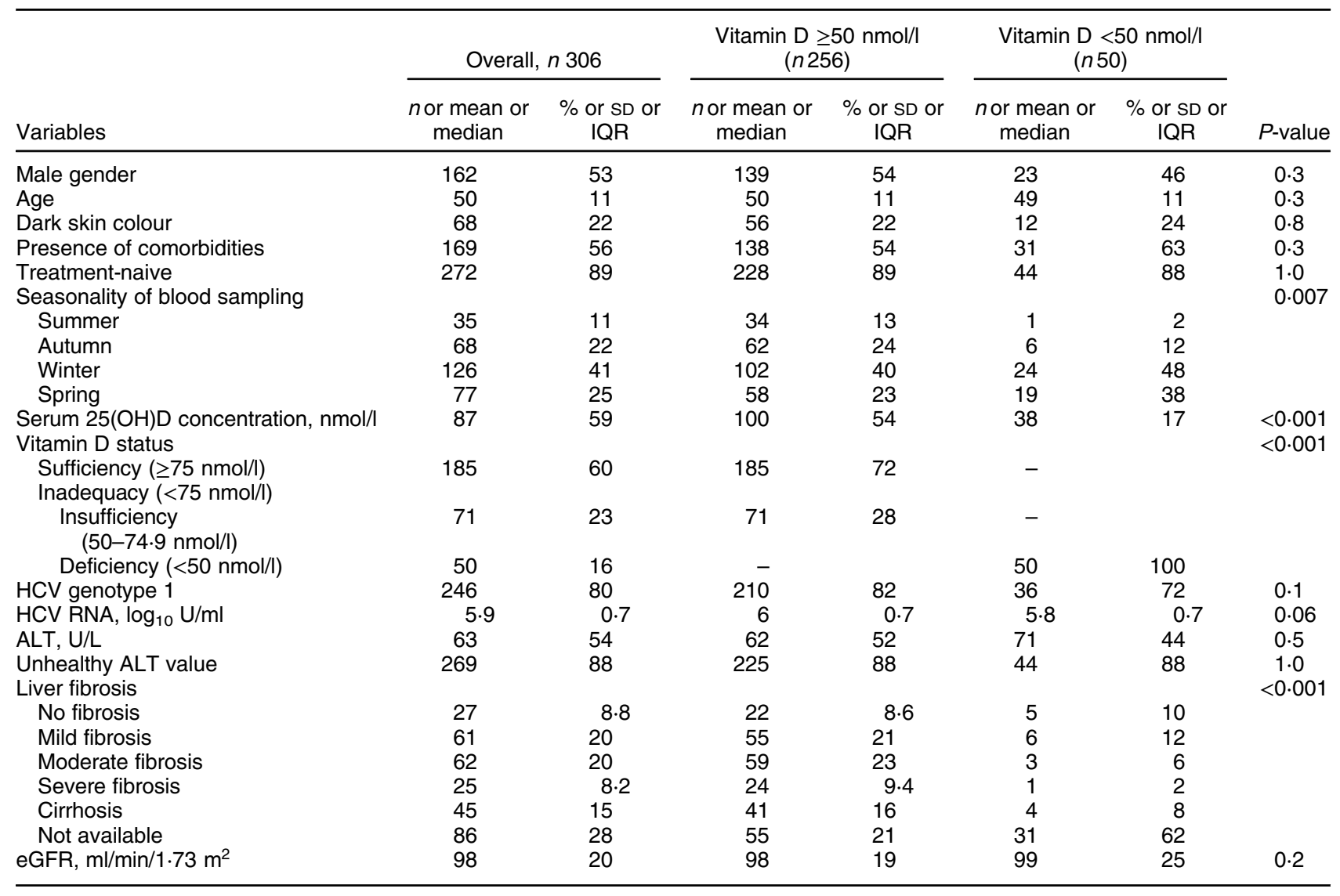

Data are presented as $n$ and \%, mean and SD, or median and IQR unless otherwise indicated. 


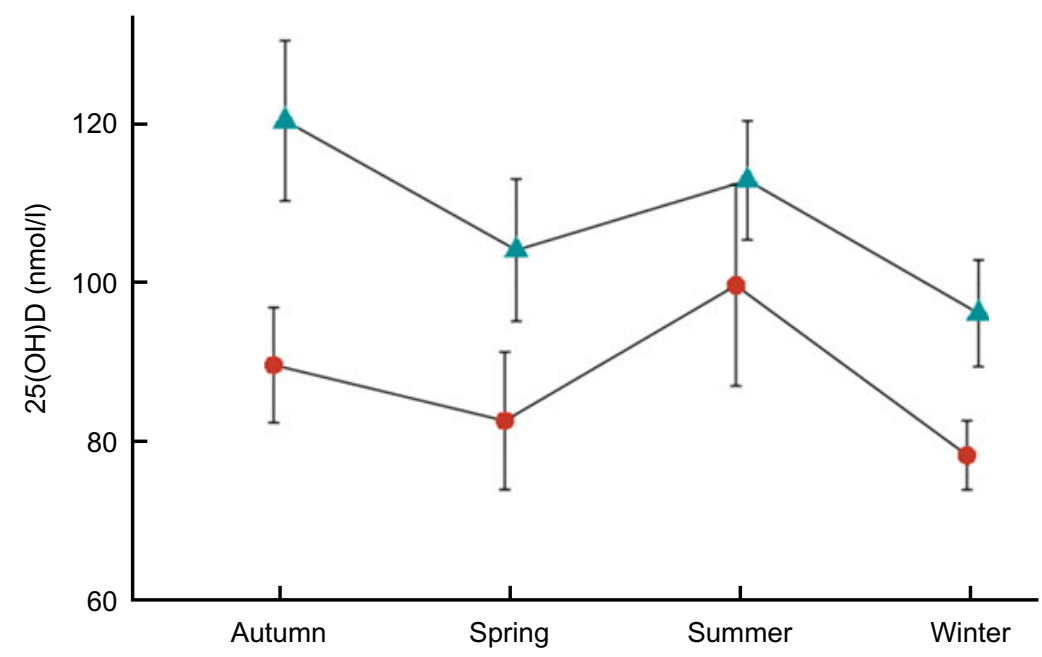

Fig. 1 (colour online) Mean serum concentration of 25(OH)D by gender and season. $\Delta$, males; $\bullet$, females

\section{Seasonality of blood sampling as an independent risk factor for vitamin $D$ inadequacy}

The relationship between vitamin D inadequacy (i.e. serum $25(\mathrm{OH}) \mathrm{D}$ concentration $<75 \mathrm{nmol} / \mathrm{l})$ and seasonality of blood sampling was further analysed using a logistic regression model adjusted for the variables whose univariate analysis obtained a $P$-value $<0 \cdot 25$, and other variables of known clinical relevance were selected for the multivariate analysis. In the first model, the presence of vitamin D inadequacy was independently associated with male gender (adjusted OR $(\mathrm{aOR})=0.4,95 \% \mathrm{CI} 0 \cdot 2,0 \cdot 7)$, serum albumin concentrations $(\mathrm{aOR}=0.4,95 \% \mathrm{CI} 0 \cdot 2,0 \cdot 9)$ and only with samples being collected in winter $(\mathrm{aOR}=2 \cdot 9,95 \% \mathrm{CI} 1$, 9.6) and spring (aOR $=2 \cdot 8,95 \%$ CI 0.9, 10) (Table 2 ).
In the second model, we sought to examine the predictors of vitamin D deficiency. As presented in Table 3, vitamin $\mathrm{D}$ deficiency was independently associated with moderate liver fibrosis $(\mathrm{aOR}=0 \cdot 1,95 \% \mathrm{CI} 0 \cdot 01,0 \cdot 8)$ and only with samples being collected in spring $(\mathrm{aOR}=6 \cdot 2,95 \% \mathrm{CI}$ $1,120)$.

\section{Discussion}

In this study of subjects with CHC infection living in São Paulo, Brazil, almost $40 \%$ had vitamin D inadequacy (i.e. serum $25(\mathrm{OH}) \mathrm{D}$ concentration $<75 \mathrm{nmol} / \mathrm{l})$. While others have reported similar findings in non-infected subjects, the literature shows a much higher prevalence

Table 2 Univariate and multivariate logistic regression for detecting the predictors of serum $25(\mathrm{OH}) \mathrm{D}$ concentration $<75 \mathrm{nmol} / \mathrm{l}$

\begin{tabular}{|c|c|c|c|c|c|c|}
\hline \multirow[b]{2}{*}{ Variables } & \multicolumn{3}{|c|}{ Univariate } & \multicolumn{3}{|c|}{ Multivariate } \\
\hline & OR & $95 \% \mathrm{Cl}$ & $P$-value & $\mathrm{aOR}$ & $95 \% \mathrm{Cl}$ & $P$-value \\
\hline Male gender & 0.4 & $0 \cdot 3,0.7$ & $<0.001$ & 0.4 & $0.2,0.7$ & 0.001 \\
\hline Age & 1 & $0.9,1$ & 0.6 & & & \\
\hline Dark skin colour & 0.9 & $0.5,1.6$ & $0 \cdot 8$ & & & \\
\hline Presence of comorbidities & 1 & $0.6,1.6$ & 0.9 & & & \\
\hline Treatment-naive & 0.7 & $0.4,1.5$ & 0.3 & & & \\
\hline \multicolumn{7}{|c|}{ Seasonality of blood sampling } \\
\hline Summer & Reference & & - & & & \\
\hline Autumn & 4 & $1 \cdot 5,12 \cdot 8$ & 0.01 & 1.8 & $0.5,6.5$ & 0.3 \\
\hline Winter & 5 & 2,15 & 0.001 & $2 \cdot 9$ & $1,9 \cdot 6$ & 0.06 \\
\hline Spring & 4 & $1 \cdot 5,13$ & 0.009 & $2 \cdot 8$ & $0.9,10$ & 0.07 \\
\hline HCV genotype 1 & $1 \cdot 2$ & $0 \cdot 7.2 \cdot 1$ & 0.5 & & & \\
\hline HCV RNA, $\log _{10} \mathrm{U} / \mathrm{ml}$ & 0.9 & $0.7,1.3$ & 0.5 & & & \\
\hline $\mathrm{ALT}, \mathrm{U} / \mathrm{I}$ & 1 & $0.9,1$ & 0.7 & & & \\
\hline Unhealthy ALT value & $1 \cdot 2$ & $0 \cdot 6,2 \cdot 6$ & 0.5 & & & \\
\hline Albumin & 0.3 & $0.1,0.5$ & $<0.001$ & 0.4 & $0.2,0.9$ & 0.03 \\
\hline \multicolumn{7}{|l|}{ Liver fibrosis } \\
\hline No fibrosis & Reference & & - & & & \\
\hline Mild fibrosis & 0.9 & $0.3,2.5$ & $0 \cdot 8$ & & & \\
\hline Moderate fibrosis & 0.3 & $0.1,0.99$ & 0.04 & 0.3 & $0.09,0.9$ & 0.03 \\
\hline Severe fibrosis & 0.5 & $0.1,1 \cdot 7$ & 0.3 & & & \\
\hline Cirrhosis & 0.7 & $0.3,2$ & 0.5 & & & \\
\hline eGFR, $\mathrm{ml} / \mathrm{min} / 1.73 \mathrm{~m}^{2}$ & 1 & $0.9,1$ & 0.3 & & & \\
\hline
\end{tabular}


Table 3 Univariate and multivariate logistic regression for detecting the predictors of serum $25(\mathrm{OH}) \mathrm{D}$ concentration $<50 \mathrm{nmol} / \mathrm{l}$

\begin{tabular}{|c|c|c|c|c|c|c|}
\hline \multirow[b]{2}{*}{ Variables } & \multicolumn{3}{|c|}{ Univariate } & \multicolumn{3}{|c|}{ Multivariate } \\
\hline & OR & $95 \% \mathrm{Cl}$ & $P$-value & aOR & $95 \% \mathrm{Cl}$ & $P$-value \\
\hline Male gender & 0.7 & $0.4,1 \cdot 3$ & 0.3 & & & \\
\hline Age & 1 & $0.9,1$ & 0.3 & & & \\
\hline Dark skin colour & 1 & $0.5,2.2$ & 0.7 & & & \\
\hline Presence of comorbidities & 1.5 & $0 \cdot 8,2 \cdot 8$ & 0.2 & $1 \cdot 2$ & $0 \cdot 6,2 \cdot 5$ & 0.7 \\
\hline Treatment-naive & 0.9 & $0.4,2.5$ & 0.8 & & & \\
\hline \multicolumn{7}{|c|}{ Seasonality of blood sampling } \\
\hline Summer & Reference & & - & & & \\
\hline Autumn & 3.3 & $0.5,63$ & 0.3 & & & \\
\hline Winter & 8 & $1 \cdot 6,145$ & 0.04 & $3 \cdot 6$ & $0.6,68$ & 0.2 \\
\hline Spring & 11 & 2,204 & 0.02 & $6 \cdot 2$ & 1,120 & 0.09 \\
\hline HCV genotype 1 & $1 \cdot 8$ & $0.9,3.5$ & 0.1 & 1.3 & $0.6,3$ & 0.5 \\
\hline HCV RNA $\left(\log _{10} \mathrm{U} / \mathrm{ml}\right)$ & 0.7 & $0.5,1$ & 0.1 & 0.7 & $0.5,1$ & 0.1 \\
\hline $\operatorname{ALT}(\mathrm{U} / \mathrm{l})$ & 1 & $0.9,1$ & 0.2 & 1 & $0.9,1$ & $0 \cdot 1$ \\
\hline Unhealthy ALT value & 1 & $0.4,2 \cdot 8$ & 1 & & & \\
\hline Albumin & 0.3 to & $0.2,0.7$ & 0.04 & 0.8 & $0.3,2$ & 0.6 \\
\hline \multicolumn{7}{|l|}{ Liver fibrosis } \\
\hline No fibrosis & Reference & & - & & & \\
\hline Mild fibrosis & 0.5 & $0.1,1 \cdot 8$ & 0.2 & 0.4 & $0 \cdot 1,1 \cdot 8$ & 0.2 \\
\hline Moderate fibrosis & 0.2 & $0.04,0.98$ & 0.05 & 0.1 & $0.01,0.8$ & 0.03 \\
\hline Severe fibrosis & 0.2 & $0.009,1.3$ & 0.1 & 0.1 & $0.007,1.2$ & 0.1 \\
\hline Cirrhosis & 0.4 & $0.09,1.8$ & 0.2 & 0.3 & $0.05,1.3$ & $0 \cdot 1$ \\
\hline $\mathrm{EGFR}, \mathrm{ml} / \mathrm{min} / 1.73 \mathrm{~m}^{2}$ & 1 & $0.9,1$ & 0.6 & & & \\
\hline
\end{tabular}

in $\mathrm{HCV}$-infected subjects ${ }^{(3)}$. In fact, we had expected a higher frequency of vitamin D inadequacy as most of the HCV-infected subjects have cumulative risk factors for hypovitaminosis $\mathrm{D}$.

However, there are several possible explanations for our findings. First, sunlight is an essential determinant of vitamin D status and stimulates the production of vitamin D3 in the skin depending on age, skin pigmentation, clothing style and sunscreen use ${ }^{(5)}$. Although the last ones were not addressed in this study, most of our subjects were middle-aged men and had light skin colour, which could explain this difference in prevalence.

Yet, as the effect of sunlight on vitamin D metabolism is dependent upon exposure to adequate sunlight wavelength, geographical location and season are considered important determinants of vitamin D status ${ }^{(4,5)}$. Regarding these aspects, in Brazil, seasonal variability of UV-B radiation reaching the earth's surface decreases proportionally with latitude. Therefore, as this study's area is located in a low-latitude region $\left(\mathrm{S} 23^{\circ} 32^{\prime}\right)$, we expected that seasonal variation of UV-B radiation would influence serum concentrations of $25(\mathrm{OH}) \mathrm{D}$. Accordingly, we found that subjects who have had their blood drawn during summer and autumn showed a higher serum $25(\mathrm{OH}) \mathrm{D}$ concentration and, thus, a lower prevalence of vitamin $\mathrm{D}$ inadequacy during those seasons. To the best our knowledge, so far, no study has been performed in subjects with $\mathrm{CHC}$ infection to assess whether the season when the blood sample was drawn is associated with the presence of vitamin D inadequacy.

Nevertheless, recent emerging evidence on the prevalence of vitamin D inadequacy in sunny countries suggests that, despite the abundance of sunlight, this condition might be a public health issue ${ }^{(5,14)}$. However, although they considered the geographical location, none have taken into account the season in which the blood was collected. In this study, we showed that blood sampling seasonality is an important preanalytical factor for the assessment of vitamin $\mathrm{D}$ inadequacy in subjects with $\mathrm{CHC}$ infection.

The overall prevalence of vitamin $\mathrm{D}$ inadequacy was rather similar to that reported in non-infected postmenopausal women (60-85 years) living in the same geographical location $^{(15)}$. Thus, considering the characteristics of our sample, $\mathrm{CHC}$ infection appears to have a significant impact in terms of reducing the age for decline in 25(OH)D and may be related to the degree of liver fibrosis and serum albumin concentration.

Serum albumin revealed to be an independent risk factor for vitamin D inadequacy and deficiency, and that a one unit increase in albumin predicted an increase of $25 \mathrm{nmol} / \mathrm{l}$ in the overall serum $25(\mathrm{OH}) \mathrm{D}$ concentration (sE $=7.03 ; P<0.001$; data not shown). Indeed, vitamin D-binding protein (DBP) and albumin are known important determinants of the overall circulatory 25(OH)D. About $90 \%$ of total vitamin D is bound with DBP, whereas $9.9 \%$ is loosely bound with albumin, and about $0.1 \%$ is present as free-circulating fraction. Therefore, the availability of $25(\mathrm{OH}) \mathrm{D}$ depends not only on the total $25(\mathrm{OH}) \mathrm{D}$ concentration but also on the concentration of DBP and albumin and the genetic background of the individual $^{(17,18)}$. For this reason, it seems reasonable that further studies should be performed to assess the impact of extrahepatic hypoalbuminemia on serum $25(\mathrm{OH}) \mathrm{D}$ concentrations. 
In the literature, there exists clear evidence that the vitamin D system plays a key role in immune modulation ${ }^{(19)}$. Therefore, by viewing $\mathrm{CHC}$ as an inflammatory disease, the nature of this relationship becomes even more important, especially when considering a possible role of the vitamin $\mathrm{D}$ system in the regulation of fibrotic process. Indeed, the vitamin $\mathrm{D}$ receptor has been shown to regulate hepatic fibrogenesis through the inhibition of hepatic stellate cell activation, down-regulation of the expression of collagen, and antagonism of the SMAD3 pro-fibrotic pathway ${ }^{(20)}$. Moreover, a recent report has shown that CHC subjects with 25(OH)D deficiency might benefit from $25(\mathrm{OH}) \mathrm{D}$ supplementation due to its role in the reversion of changes in serum fibrogenic cytokine and enzymes to the pro-fibrolytic state ${ }^{(21,22)}$. Therefore, from a public health perspective, these data suggest a need for further studies to assess the impact of vitamin D sufficiency on CHC infection with respect to its possible role in the progression of liver fibrosis.

The results of this study should be interpreted with the following limitations in mind. First is the cross-sectional design of this study, which does not provide evidence of a temporal relationship between blood sampling seasonality and vitamin D inadequacy. On the other hand, as the study variables were assessed at the same time, bias owing to variations between independent and dependent variables within the same individual was reduced. Moreover, other confounding factors such as variation in age, gender and skin pigmentation were also controlled. Another limitation was the lack of information on serum $1,25(\mathrm{OH}) \mathrm{D}$ concentration, genetic analysis of SNPs of genes encoding DBP and 25-hydroxylase, and other potential confounders such as clothing style and sunscreen use. Despite these limitations, the study provides evidence on the importance of blood sampling seasonality as an important preanalytical factor for the assessment of vitamin $\mathrm{D}$ inadequacy in subjects with $\mathrm{CHC}$ infection.

In conclusion, this cross-sectional study demonstrated a rather low prevalence of vitamin D inadequacy among CHC-infected subjects in a sunny country. The occurrence of vitamin D deficiency was independently associated with male gender, serum albumin concentration and with samples drawn in winter and spring. These findings reaffirm not only the relevance to consider season as a factor influencing 25(OH)D concentration but also the need to actively screen for hypovitaminosis $\mathrm{D}$ in all patients with $\mathrm{CHC}$ infection, especially in females and those with low albumin concentration.

\section{Acknowledgements}

Acknowledgements: We thank MJR Vaz as well as the nursing staff of the Viral Hepatitis Outpatient Clinic for help with recruiting patients. Financial support: This research received no specific grant from any funding agency, commercial or not-for-profit sectors. Conflict of interest: All authors have no conflicts of interests to disclose. Authorship: All authors had full access to the study data and assume responsibility for data integrity and analytical accuracy. H.P. Jr is the guarantor. The dataset is available from the corresponding author on reasonable request. Ethics of human subject participation: This study was conducted according to the guidelines laid down in the Declaration of Helsinki and all procedures involving human subjects/patients were approved by the Universidade Federal de São Paulo's Research Ethics Committee. Written informed consent was waived by the Institutional Review Board because of the retrospective nature of the study, and the analysis used anonymous clinical data.

\section{References}

1. Jin C-N, Chen J-D \& Sheng J-F (2018) Vitamin D deficiency in hepatitis $\mathrm{C}$ virus infection: what is old? What is new? Eur J Gastroenterol Hepatol 30, 741-746.

2. Buonomo AR, Zappulo E, Scotto R et al. (2017) Vitamin D deficiency is a risk factor for infections in patients affected by HCV-related liver cirrhosis. Int J Infect Dis 63, 23-29.

3. Melo-Villar L, Lampe E, de Almeida AJ et al. (2015) Hypovitaminosis D and its relation to demographic and laboratory data among hepatitis C patients. Ann Hepatol 14, 457-463.

4. Bonelli P, Buonocore R, Aloe R et al. (2016) Blood sampling seasonality as an important preanalytical factor for assessment of vitamin D status. J Med Biochem 35, 113-117.

5. Mendes MM, Hart KH, Botelho PB et al. (2018) Vitamin D status in the tropics: Is sunlight exposure the main determinant? Nutr Bull 43, 428-434.

6. Levey AS, Bosch JP, Lewis JB et al. (1999) A more accurate method to estimate glomerular filtration rate from serum creatinine: a new prediction equation. Modification of Diet in Renal Disease Study Group. Ann Intern Med 130, 461-470.

7. Chou R \& Wasson N (2013) Blood tests to diagnose fibrosis or cirrhosis in patients with chronic hepatitis $\mathrm{C}$ virus infection: a systematic review. Ann Intern Med 158, 807.

8. Lin Z-H, Xin Y-N, Dong Q-J et al. (2011) Performance of the aspartate aminotransferase-to-platelet ratio index for the staging of hepatitis C-related fibrosis: an updated metaanalysis. Hepatology 53, 726-736.

9. Prati D, Taioli E, Zanella A et al. (2002) Updated definitions of healthy ranges for serum alanine aminotransferase levels. Ann Intern Med 137, 1.

10. Vogeser M (2004) Candidate reference method for the quantification of circulating 25 -hydroxyvitamin D3 by liquid chromatography-tandem mass spectrometry. Clin Chem 50, 1415-1417.

11. Phinney KW (2008) Development of a standard reference material for vitamin D in serum. Am J Clin Nutr 88, 511S-512S

12. Wielders JP, Carter GF, Eberl H et al. (2015) Automated competitive protein-binding assay for total $25-\mathrm{OH}$ vitamin $\mathrm{D}$, multicenter evaluation and practical performance: multicenter evaluation of total 25-OHD assay. J Clin Lab Anal 29, 451-461.

13. Holick MF, Binkley NC, Bischoff-Ferrari HA et al. (2011) Evaluation, treatment, and prevention of vitamin D deficiency: an Endocrine Society clinical practice guideline. J Clin Endocrinol Metab 96, 1911-1930. 
14. Maeda SS, Borba VZC, Camargo MBR et al. (2014) Recommendations of the Brazilian Society of Endocrinology and Metabology (SBEM) for the diagnosis and treatment of hypovitaminosis D. Arq Bras Endocrinol Metabol 58, 411-433.

15. Arantes HP, Kulak CAM, Fernandes CE et al. (2013) Correlation between 25-hydroxyvitamin D levels and latitude in Brazilian postmenopausal women: from the Arzoxifene Generations Trial. Osteoporos Int 24, 2707-2712.

16. Kuchuk NO, van Schoor NM, Pluijm SM et al. (2009) Vitamin D status, parathyroid function, bone turnover, and BMD in postmenopausal women with osteoporosis: global perspective. J Bone Miner Res 24, 693-701.

17. Jemielita TO, Leonard MB, Baker J et al. (2016) Association of 25-hydroxyvitamin D with areal and volumetric measures of bone mineral density and parathyroid hormone: impact of vitamin D-binding protein and its assays. Osteoporos Int $\mathbf{2 7}$, 617-626.

18. Chun RF (2012) New perspectives on the vitamin D binding protein. Cell Biochem Funct 30, 445-456.

19. Sassi F, Tamone C \& D'Amelio P (2018) Vitamin D: nutrient, hormone, and immunomodulator. Nutrients 10, 1656.

20. Udomsinprasert W \& Jittikoon J (2019) Vitamin D and liver fibrosis: molecular mechanisms and clinical studies. Biomed Pharmacother 109, 1351-1360.

21. Komolmit P, Kimtrakool S, Suksawatamnuay S et al. (2017) Vitamin D supplementation improves serum markers associated with hepatic fibrogenesis in chronic hepatitis $\mathrm{C}$ patients: a randomized, double-blind, placebo-controlled study. Sci Rep 7, 8905 .

22. Song B-J \& Rockey DC (2013) Status of research on vitamin D supplementation in treating or preventing liver fibrosis. Liver Int 33, 653-655. 